\title{
Highly Sensitive Ferromagnetic Resonance Measurements Using Coplanar Waveguides
}

\author{
N. Toda, K. Saito, K. Ohta, H. Maekawa, M. Mizuguchi, M. Shiraishi, and Y. Suzuki \\ Graduate School of Engineering Science, Osaka University, 1-3 Machikaneyama, Toyonaka, Osaka 560-8531, Japan
}

\begin{abstract}
Ferromagnetic resonance (FMR) measurements using coplanar waveguides (CPWs) make it possible to perform highly sensitive magnetization measurements, since a CPW can concentrate electromagnetic waves onto a narrow signal line. In this study, we aimed to perform FMR measurements of a minute individual magnet, and investigated the dependence of the sensitivity on the signal line width. We fabricated CPWs on $\mathrm{MgO}$ wafers and placed an individual $\mathrm{NiFe}$ dot on each of CPWs. NiFe dots with a thickness of $30 \mathrm{~nm}$ and various lateral sizes, i.e. $50 \times 100,50$ $\times 80,50 \times 30,50 \times 20$, and $50 \times 10 \mu \mathrm{m}$, were fabricated. The signal line widths of these samples were 150, 100, 50, 30, and $15 \mu \mathrm{m}$, respectively. The external magnetic field dependence of the resonance frequency was well fitted by Kittel's formula. As expected, we obtained larger signals from smaller samples, because narrower signal lines that create larger rf fields were employed for smaller samples.
\end{abstract}

Key words: FMR, coplanar waveguide, precession, microwave, microfabrication

\section{コプレーナウェーブガイドを用いた強磁性共鳴の高感度測定}

戸田順之・斎藤和広・太田健太・前川裕昭・水口将輝 - 白石誠司 - 鈴木義茂

大阪大学大学院基礎工学研究科, 大阪府豊中市待兼山町 1-3（ ₹ 560-8531）

\section{1. はじめに}

近年, デバイスの高密度化，多機能化がますます求められるよ うになり, 電子の電荷に加えもう一つの重要な性質であるスピン を利用した，スピントロニクスが注目されるようになってきた。 その一例である磁気ランダムアクセスメモリ (MRAM)1）の記録 セルにおいて，その小型化を図るには，非常に小さなサイズにお ける磁生体のダイナミクスを解明する必要がある。 そこで我々は, 磁化ダイナミクスの測定法の一つである強磁性共鳴 (FMR) に注 目した。 従来の FMR 測定では，導波管と共鳴器を用いていたた め, 測定が一つの周波数領域に限られ，試料のサイズも制約を受 けていた2).しかし，微細加工技術の進歩により，導波管をウェー ブガイドで代替することで，広い周波数領域での測定とともに， ウェーブガイドの狭い信号線上に高周波磁界を集中させることで より小さな試料での FMR 測定が可能となってきた ${ }^{3,4}$. 特にウェ ーブガイドを用いると過渡応答を時間領域で測定できるという優 れた点もある5).

本論文では, 微小磁生体の周波数領域での FMR の測定法につ いて報告する. これまでにも非常に小さな磁性体の FMR をウェ ーブガイドを用いて測定した例はあるが，信号を大きくするため に多数の試料を同一のウェーブガイドの信号線上に集積して測定 する必要があった6).これに対して本論文では, 単一の微小磁生体 においてどこまで小さな試料の測定が可能であるかを明らかにす るために，ウェーブガイドの信号線幅が FMR 信号強度に与える 影響について調べた．またここでは，周波数領域の測定について 報告するが，時間領域の測定も同様に行うことが出来る.

\section{2. 実験方法}

Fig. 1 に試料の構造と測定の概念図を示す. $\mathrm{MgO}$ 基板（厚さ：
$500 \mu \mathrm{m})$ 上に信号線と接地線からなる $\mathrm{Cr}(5 \mathrm{~nm}) / \mathrm{Cu}(150 \mathrm{~nm}) /$ $\operatorname{Cr}(5 \mathrm{~nm})$ で構成されるウェーブガイドを真空蒸着法とリフトオフ 法により作製した．その信号線上にサンプルとして酸化防止のた め $\mathrm{Au}(5 \mathrm{~nm})$ キャップをした $\mathrm{NiFe}(30 \mathrm{~nm})$ を配置した. なお，ウェ ーブガイドとしてはサンプル部における電流の強度を大きくする ために信号線と接地線が右端で接続されたショート型のコプレー ナウェーブガイドを採用した. コプレーナウェーブガイドとは, 誘電体基板の上に例えば50 $\mu \mathrm{m}$ 程度の幅の信号線とその両側に 22 $\mu \mathrm{m}$ 程度の幅のギャップを隔てて接地線が設けられた構造の伝送 線路をいう. 基板の誘電率と信号線幅に合わせてギャップ幅を適 当に調整することでインピーダンスマッチングをとることが出来 る. 本実験では, $\mathrm{MgO}$ 基板（誘電率 $\varepsilon_{\mathrm{r}}=9.65 ） 7$ )において伝送線 路の特性インピーダンスが $50 \Omega$ となるように信号線幅とギャッ プ幅の比率はどの試料においても $25: 11$ とした8).

測定を行った 5 種類のサンプル形状を Fig. 2 に示寸. 微小磁生 体の FMR 測定を可能にする手段として，信号線幅を狭くするこ との有効性を調べるため, 横方向のサンプル $(\mathrm{Au} / \mathrm{NiFe})$ サイズ

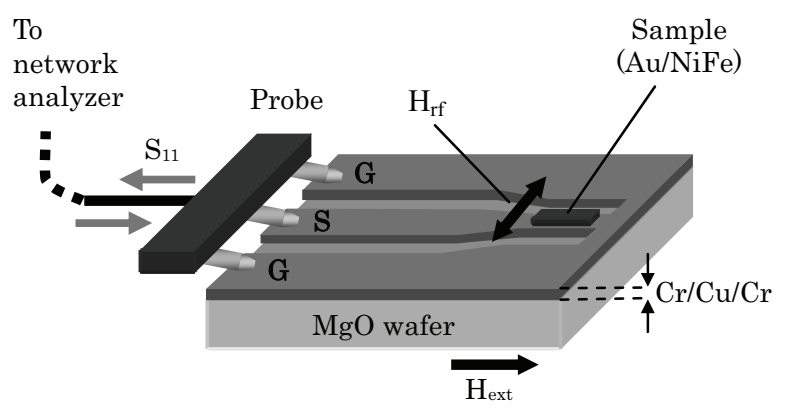

Fig. 1 Schematic diagram of a sample on a coplanar waveguide with a signal line width of $30 \mu \mathrm{m}$, and the experimental setup (S: signal line, G: ground line). 

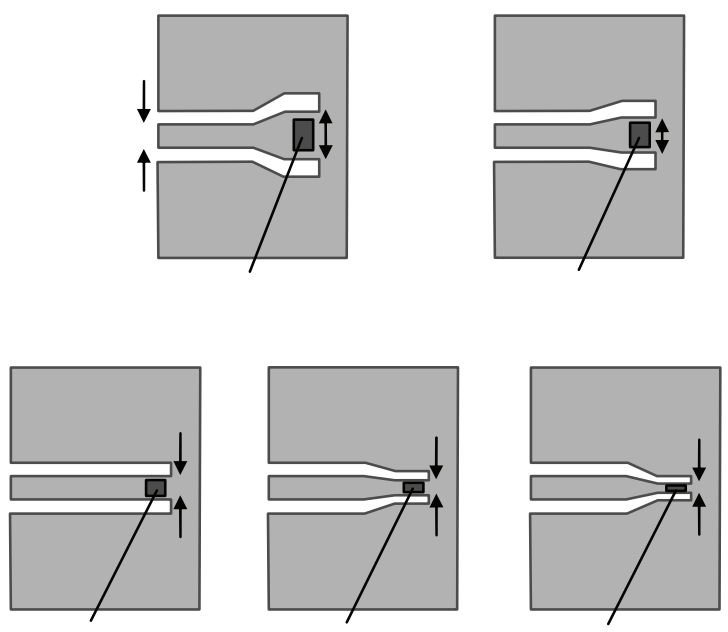

Fig. 2 Top view of the sample on the coplanar waveguide. $\mathrm{NiFe}$ dots with a thickness of $30 \mathrm{~nm}$ and various lateral sizes, i.e. $50 \times 100,50 \times 80,50 \times 30,50 \times 20$, and $50 \times$ $10 \mu \mathrm{m}$, were fabricated. The signal line widths of these samples were $150,100,50,30$, and $15 \mu \mathrm{m}$, respectively.

を $50 \mu \mathrm{m}$ で一定とし, 縦方向のサイズを $100,80,30,20,10 \mu \mathrm{m}$ と小さくするとともに試料直下のウェーブガイドの信号線幅も 150，100，50，30，15 $\mu \mathrm{m}$ と狭くしたサンプルウェーブガイド

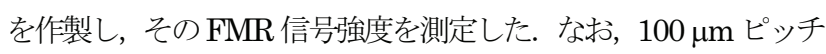
の GSG (Ground/Signal/Ground）型のプローバーで接触をとる ために, ウェーブガイドの左端の信号線幅は $50 \mu \mathrm{m}$ とし, 左端の 信号線と試料直下の信号線をつなぐ部分では 15 度の絞り角 (開き 角）となるように信号線の幅を変化させた.

この 5 種類のサンプルそれぞれに対して, Fig. 1 のようにプロー バーによりウェーブガイドとの接触をとり, ネットワークアナラ イザーで高周波の振幅反射率 $\left(\mathrm{S}_{11}=V_{\text {out }} / V_{\text {in }}\right.$; ただし, $V_{\text {in }}$ は入力電 圧， $V_{\text {out }}$ は出力電圧を意味する）を測定した. 外部磁界を信号線と 平行な方向に印加することによりサンプルを信号線の方向に磁化 した状態で，ウェーブガイドに高周波電流を流すと，信号線と垂 直な方向に高周波磁界が発生して試料の磁化にトルクを与える. その結果, 試料の磁化の歳差運動が促される. 歳差運動が生じる と, インダクタンスが増大寸るため $\mathrm{S}_{11}$ が変化する. すなわち, $\mathrm{S}_{11}$ の変化を測定することにより磁化の共鳴的な応答を検出すること できる.

サンプルサイズが $50 \times 10 \mu \mathrm{m}$ の試料において，外部磁界を信号 線と平行方向に 550 Oe 印加した時の試料の反射率 $\mathrm{S}_{11 \text {, para }}$ の実部, 虚部, 絶対值を Fig. 3 に示寸. 本実験ではショート型のウェーブ ガイドを用いているので, 原理的には $\mathrm{S}_{11, \text { para }}$ の実部は一1 になる はずである. しかし，Fig. 3をみると一1からずれており，そのず れは周波数が上がるほど大きくなる. 周波数のゼロ近くにおいて も-1にならないのは, ウェーブガイドの実抵抗のためである. ま た，高周波数側での実部のずれ，そして虚部の増大はウェーブガ イドによる信号の時間遅れに起因寸る. 次に周波数が上がるにつ れて $\mathrm{S}_{11 \text {,para }}$ の絶対值が減少するのはウェーブガイドに減衰がある

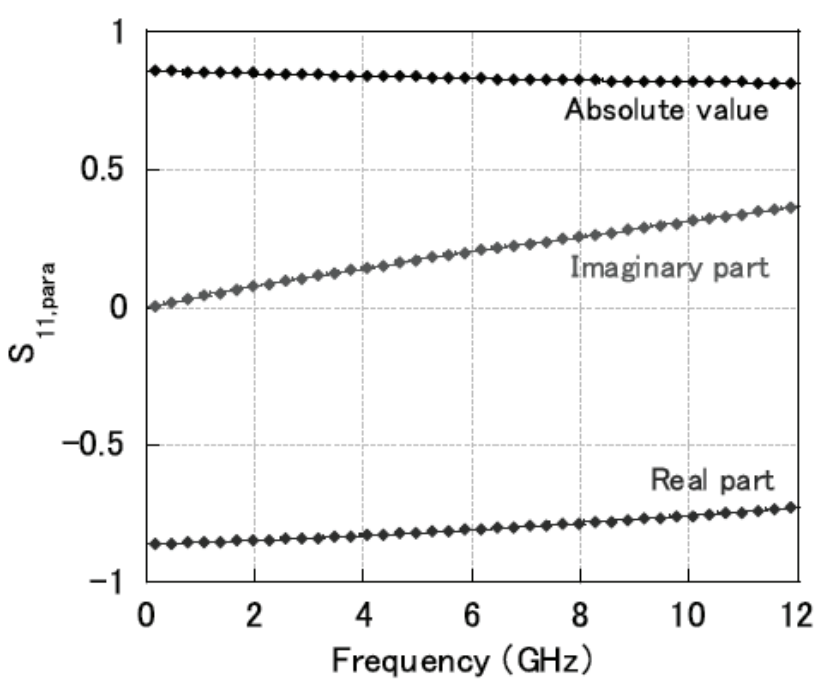

Fig. 3 Real part, imaginary part, and absolute value of the reflectivity $S_{11 \text {,para }}$ obtained by using a sample with a size of $50 \times 10 \mu \mathrm{m}$. This measurement was performed under an external magnetic field of 550 Oe.

ためである.これらを全てモデル化すると(1)式で表される.

$$
S_{11, \text { para }}=\left(S_{11}(0)+\Delta S_{11}\right) e^{2 \pi i f(\tau+i \kappa)} .
$$

ここで， $\mathrm{S}_{11}(0)$ は周波数ゼロにおける反射率， $\Delta \mathrm{S}_{11}$ は試料の共鳴 による反射率の変化， $f$ は周波数， $\tau$ はウェーブガイドによる時間 遅れ（今回は数百 psecであり，ウェーブガイドの長さから期待さ れる時間遅れとなっている), $\kappa$ は減衰定数である. Fig. 3 の信号 には(1)式に示したように試料による反射率の変化 $\Delta \mathrm{S}_{11}$ が含まれ ているが, $\Delta \mathrm{S}_{11}$ は非常に小さくこのままでは見ることができない.

そこで, 外部磁界を信号線と垂直方向に $100 \mathrm{Oe}$ 印加し, 試料の 磁化にトルクがかからない状態で反射率 $\mathrm{S}_{11, \text { perp }}$ を測定した.

$$
S_{11, p e r p}=S_{11}(0) e^{2 \pi i f(\tau+i \kappa)} .
$$

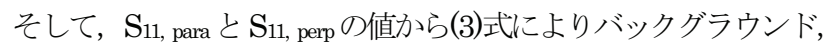
強度および位相の補正を行い，純粋な FMR による信号の変化 $\Delta$ $\mathrm{S}_{11}$ を求めた。

$$
\Delta S_{11}=S_{11}(0)\left(S_{11, \text { para }}-S_{11, \text { perp }}\right) / S_{11, \text { perp }} .
$$

このことにより, 試料の共鳴による $\mathrm{S}_{11}$ の変化を高感度に測定でき るとともに, 定量的な測定が可能となる. なお，今回の測定周波 数 (50GHz以下) では, 高周波は準 TEM モードで伝送している と考えられる8).

\section{3. 実験結果及び考察}

作製した 5 種類の試料において FMR 測定を行った結果，全て の試料で FMR による信号の変化を確認できた. サンプルサイズ が $50 \times 10 \mu \mathrm{m}$ の試料における $\Delta \mathrm{S}_{11}$ の実部と虚部を Fig. 4 に示す. 室温下で, 高周波電力を- $15 \mathrm{dBm}(\fallingdotseq 31.6 \mu \mathrm{W})$ 投入し, 外部磁 界の大きさを 0 ～650 Oe と変化させて測定を行った（3)式により 

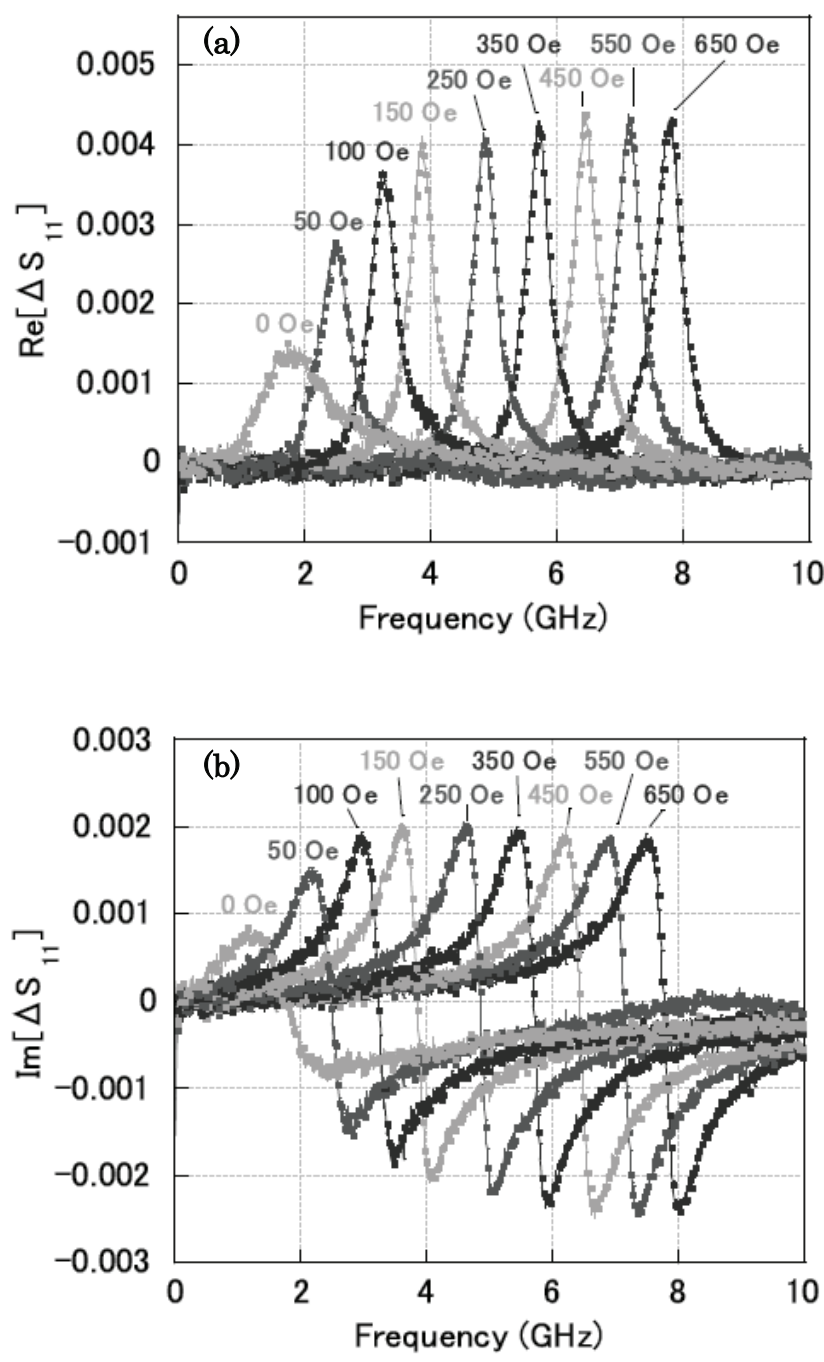

Fig. 4 (a) FMR spectra of $\operatorname{Re}\left[\Delta \mathrm{S}_{11}\right]$ (the real part of $\Delta \mathrm{S}_{11}$ ) obtained by using a sample with a size of $50 \times 10 \mu \mathrm{m}$. (b) FMR spectra of $\operatorname{Im}\left[\Delta \mathrm{S}_{11}\right]$ (the imaginary part of $\Delta \mathrm{S}_{11}$ ). Each spectrum was measured under an external magnetic field $(0-650$ Oe).

Fig. 3 に示したバックグラウンドがほぼ完全に取り除かれ, 実部に は上に凸なピーク状，虚部には分散型の FMR スペクトルが明瞭 な形として観測された.このピークは外部磁界を大きくしていく につれて, 高周波側ヘシフトしていった. これは(4)式に表される 共鳴周波数と外部磁界の関係 9 )によく一致する.

$$
f=\frac{|\gamma|}{2 \pi} \sqrt{\left(H_{a, / /}+H_{e x t}\right)\left(H_{a, \perp}+H_{e x t}\right)} .
$$

ここで, $f$ は共鳴周波数, $\gamma$ はジャイロ磁気定数 $(\gamma<0), H_{\mathrm{a}, / /}$ は

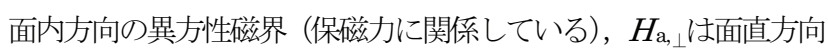
の異方性磁界 (反磁界にほぼ一致する), $H_{\text {ext }}$ は外部磁界を表す. 実験で得られた共鳴周波数と外部磁界の関係を(4)式でフィッティ

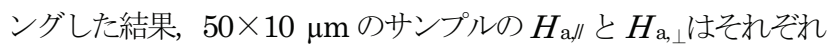
$35 \mathrm{Oe}$ と $9390 \mathrm{Oe}$ となった. $H_{\mathrm{a}, /}$ はサンプルサイズが $50 \times 20 \mu \mathrm{m}$, $50 \times 30 \mu \mathrm{m}, 50 \times 80 \mu \mathrm{m}, 50 \times 100 \mu \mathrm{m}$ と変化すると, $28 \mathrm{Oe}, 17$

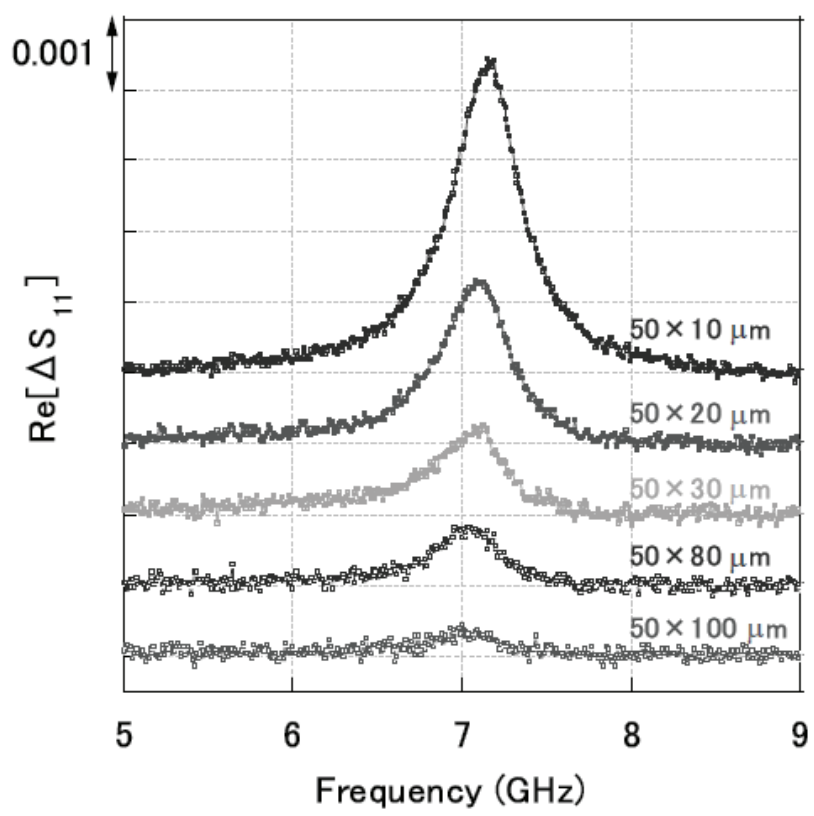

Fig. 5 Sample size dependence of the FMR signal intensity. Each spectrum was measured under an external magnetic field of 550 Oe.

Oe, $14 \mathrm{Oe}, 13 \mathrm{Oe}$ と変化していった. これは, サンプル形状の 縦横比が変化したことに起因するものである，なお， $H_{\mathrm{a}, \text { はどの }}$ サンプル形状においてもほぼ同じ值で, $\mathrm{NiFe} の$ 飽和磁化 $1.05 \mathrm{~T}$ と比較してもある程度妥当な值が得られていることが分かる.

次に $\Delta \mathrm{S}_{11}$ の実部で得られた FMR スペクトルの線幅より, 磁化 の歳差運動におけるダンピング定数 $\alpha$ を求めた. スペクトルの半值 幅 $\Delta f$ は次のような式で表される4).

$$
\begin{aligned}
& \Delta f=\alpha\left(f_{/ /}+f_{\perp}\right) . \\
& f_{/ /}=-\frac{\gamma}{2 \pi}\left(H_{a, /}+H_{e x t}\right), f_{\perp}=-\frac{\gamma}{2 \pi}\left(H_{a, \perp}+H_{e x t}\right) .
\end{aligned}
$$

そこで, $550 \mathrm{Oe}$ の外部磁界を印加した時の FMR スペクトルの半

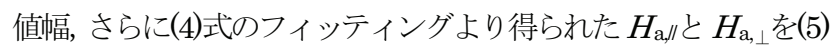
式に代入すると, $50 \times 10 \mu \mathrm{m}, 50 \times 20 \mu \mathrm{m}, 50 \times 30 \mu \mathrm{m}, 50 \times 80$ $\mu \mathrm{m}, 50 \times 100 \mu \mathrm{m}$ それぞれのサンプルにおけるダンピング定数は 0.0145, 0.0143, 0.0141, 0.0138, 0.0138 となった. これらの值はい ずれも FMRの実験で得られているバルクの NiFeにおけるダンピ ング定数の值 0.008 に比べて大きな值となっている. この原因は 定かではないが, $\mathrm{NiFe}$ の成膜段階での成長様式に起因する異方性 分散, サンプル側面での $\mathrm{NiFe}$ の酸化, 高周波磁界の不均一性など の影響によりサンプル内の磁化の歳差運動が完全に一様ではなく, 共鳴周波数がわずかに異なり, 全体として半值幅の広がりとなっ たのかもれない.

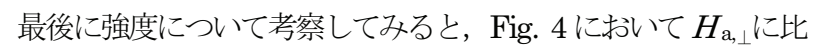
べて外部磁界が無視できるほど小さい領域では, 外部磁界が大き くなると信号強度が一定となる様子が観測された. そこで, 5 種類 の試料において信号強度が一定となる外部磁界の大きさ (550 Oe) で $\Delta \mathrm{S}_{11}$ を測定し，ウェーブガイドの信号線幅が信号強度に与える 影響を調べた. Fig. 5 に各サンプルサイズと $\Delta \mathrm{S}_{11}$ の実部での信号 
強度の関係を示す. 強度の比較を容易にするため, 各スペクトル は 0.001 ずつ縦軸方向にシフトしている. サンプルサイズが小さ くなると信号強度に寄与寸る磁性体の体積が小さくなるのにも関 わらず徐々に信号強度は大きくなり，一番小さい試料において最 も大きな信号強度が得られた. これはサンプルサイズを小さくす るとともにウェーブガイドの信号線幅を狭くし高周波磁界を増大 させたことで, サンプルに大きな歳差運動が誘起されたことに起

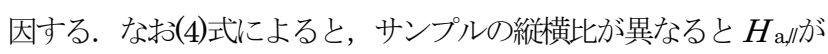
異なるため, 同じ大きさの外部磁界を印加していてもわずかに共 鳴周波数が変化すると予想される. 今回の実験ではそのわずかな 共鳴周波数の変化も観測された.

以上より，ウェーブガイドを用いた FMR 測定で微小磁生体の ダイナミクスを簡便に測定するには，ウェーブガイドの信号線幅 を狭くすることが有効であることが分かった，今回は信号線幅を 最小で $15 \mu \mathrm{m}$ まで狭くし測定を行ったが，さらに信号線幅を狭く することでナノスケールといった非常に小さな磁性体の測定も可 能であると思われる．実際には，信号線幅がウェーブガイドの膜 厚と同程度の值まで狭くなると，発生する高周波磁界が減少する とともに, ウェーブガイド自体の抵抗が無視できなくなり特性イ ンピーダンスにずれが生じてくるので, これらがこの手法による FMR 測定の限界を決めるはずである.

\section{4. まとめ}

ショート型のウェーブガイドを使用し，その信号線幅の FMR 信号強度への影響を調べた.今回作製した全てのサイズのサンプ ルにおいて，十分な $\mathrm{S} / \mathrm{N}$ 比の FMR 信号が確認され，そのスペク

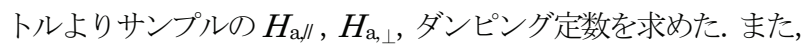
信号強度に関してサンプルサイズを小さくするとともにウェーブ
ガイドの信号線幅も狭くした結果, サンプルの磁化に歳差運動を 促す高周波磁界の増大が実現され, 予想していた通り一番小さい サンプルにおいて最大の信号強度が得られた. 以上より, 微小磁 性体の FMR 測定を可能にする手段として, ウェーブガイドの信 号線幅を狭くすることが有効であることが明らかになった. 今後, 信号線幅が $15 \mu \mathrm{m}$ 以下のウェーブガイドを作製することにより, さらに高感度で簡便な磁化測定が実現されるとともに, ウェーブ ガイドを用いた FMR の測定限界を調べ, 測定法自体の確立に貢 献できると思われる.

謝辞 本研究の一部は財団法人 三菱財団の補助により行われた.

\section{References}

1) G. A. Prinz: Science 250, 1092 (1990).

2) J. H. E. Griffiths: Nature 158, 670 (1946).

3) G. Counil, J-V. Kim, K. Shigeto, Y. Otani, T. Devolder, P. Crozat, H. Hurdequint, and C. Chappert: J. Magn. Magn. Mater. 272, 290 (2004).

4) G. Counil, J-V. Kim, T. Devolder, C. Chappert, K. Shigeto, and Y. Otani: J. Appl. Phys. 95, 5646 (2004).

5) T. J. Silva, C. S. Lee, T. M. Crawford, and T. Rogers: J. Appl. Phys. 85, 7849 (1999).

6) V. Novosad, F. Y. Fradin, P. E. Roy, K. S. Buchanan, K. Yu. Guslienko, and D. Bader: Phys. Rev. B 72, 024455 (2005).

7) M. Kamiyama: Thin Film Handbook, p. 13(Ohmsha, Tokyo, 1983).

8) K. Honjou: Tyoukousyuuha Erekutoronikusu nyuumon (in Japanese), p.74 and p. 78(Nikkankougyoushinbunsya, Tokyo, 1999).

9) C. Kittel: Introduction to Solid State Physics, 6th eds. P.481(John Wiley and Sons Inc., New York 1986).

2006 年 12 月 06 日受理、2007 年 9 月 11 日採録 